\title{
Hospital Costs of Extracorporeal Membrane Oxygenation in Adults: A Systematic Review
}

\author{
Annemieke Oude Lansink-Hartgring ${ }^{1}$ (1) . Olivier van Minnen ${ }^{1} \cdot$ Karin M. Vermeulen ${ }^{2} \cdot$ Walter M. van den Bergh $^{1}$ \\ on behalf of the Dutch Extracorporeal Life Support Study Group
}

Accepted: 29 April 2021 / Published online: 31 May 2021

(c) The Author(s) 2021

\begin{abstract}
Background Costs associated with extracorporeal membrane oxygenation (ECMO) are an important factor in establishing cost effectiveness. In this systematic review, we aimed to determine the total hospital costs of ECMO for adults.

Methods The literature was retrieved from the PubMed/MEDLINE, EMBASE, and Web of Science databases from inception to 4 March 2020 using the search terms 'extracorporeal membrane oxygenation' combined with 'costs'; similar terms or phrases were then added to the search, i.e. 'Extracorporeal Life Support' or 'ECMO' or 'ECLS' combined with 'costs'. We included any type of study (e.g. randomized trial or observational cohort) evaluating hospital costs of ECMO in adults (age $\geq 18$ years).

Results A total of 1768 unique articles were retrieved during our search. We assessed 74 full-text articles for eligibility, of which 14 articles were selected for inclusion in this review; six papers were from the US, five were from Europe, and one each from Japan, Australia, and Taiwan. The sample sizes ranged from 16 to 18,684 patients. One paper exclusively used prospective cost data collection, while all other papers used retrospective data collection. Five papers reported charges instead of costs. There was large variation in hospital costs, ranging from US\$22,305 to US $\$ 334,608$ (2019 values), largely depending on the indication for ECMO support and location. The highest reported costs were for lung transplant recipients who were receiving ECMO support in the US, and the lowest reported costs were for extracorporeal cardiopulmonary resuscitation patients presenting with non-shockable rhythm in Japan. The additional costs of ECMO patients compared with non-ECMO patients varied between US\$2518 and US\$200,658. Personnel costs varied between 11 and 52\% of the total amount.

Conclusions ECMO therapy is an advanced and expensive technology, although reported costs differ considerably depending on ECMO indication and whether charges or costs are measured. Combined with the ongoing gathering of outcome data, cost effectiveness per ECMO indication could be determined in the future.
\end{abstract}

\section{Introduction}

Extracorporeal membrane oxygenation (ECMO) is the use of mechanical support to temporarily (days to months) support heart and/or lung function (partially or totally)

The members of Dutch Extracorporeal Life Support Study Group are listed in Acknowledgements section.

Annemieke Oude Lansink-Hartgring a.oudelansink@umcg.nl

1 Department of Critical Care, University of Groningen, University Medical Center Groningen, Hanzeplein 1, 970 RB Groningen, The Netherlands

2 Department of Epidemiology, University of Groningen, University Medical Center Groningen, Groningen, The Netherlands

\section{Key Points for Decision Makers}

Extracorporeal membrane oxygenation (ECMO) therapy is an advanced and expensive technology with a large variation in hospital costs.

For the US studies, the hospital costs for ECMO seem higher than in the non-US studies.

Length of stay is one of the most important factors in total costs. 
during cardiopulmonary failure when conventional treatments have failed, until recovery or permanent device implant or organ transplantation [1]. The H1N1 outbreaks, combined with technical advances in mechanical devices and disposables, led to renewed interest and subsequent worldwide expansion in use. Between 2008 and 2019, the use of ECMO increased exponentially, with a total of 130,000 reported runs [2]. It is likely use will increase further as new centers worldwide start an ECMO program, due to expanding indications (coronavirus disease 2019 [COVID-19]), and if ongoing trials in extracorporeal cardiopulmonary resuscitation (ECPR) and carbon dioxide removal show positive results.

An ECMO program depends on highly advanced technology, is labor intensive, and requires highly specialized personnel. Revenue from ECMO will depend on the regional/national healthcare reimbursement system, which ranges from no reimbursement (e.g. The Netherlands) to partial reimbursement or special extra budgetary compensation (e.g. Germany and Belgium). A previous systematic review on in-hospital costs in neonates, pediatrics and adults showed costs varying between US $\$ 42,554$ and US $\$ 537,554$ (in 2013 values) [3]. To perform an economic evaluation, one needs to compare the relative costs (resource use) of medical interventions with their effectiveness (health effects). Despite the results of two randomized controlled trials in adult respiratory distress syndrome (ARDS), the deployment of ECMO is still not undisputed with regard to proven benefit in all the different patient categories in which it is used [4,5]. Subgroup differences in the treatment effect of ECMO should be considered when evaluating the costs of ECMO therapy. Ordinarily, proven benefit should be the starting point for the evaluation of cost effectiveness [6,7]. In an economic evaluation of a hypothetical cohort, it is suggested that venovenous ECMO is likely cost effective for young adult patients with severe ARDS [8].

The benefit of ECMO support is not beyond any doubt, although ECPR is considered life-saving, which explains why cost-effectiveness studies for ECPR are surging in the literature [9-14]. In critical care, one might accept that very expensive treatment modalities are necessary, but, when used increasingly, this leads to an escalation of costs. If the critical care community is not in the lead in performing cost (effectiveness) studies, external organizations might perform these studies and institute policies.

The primary objective of this study was to conduct a systematic review to determine the total hospital costs of ECMO (the in-hospital treatment and procedural costs of ECMO), in both US and non-US settings. Our secondary objective was to identify subgroups in diagnosis categories (respiratory, cardiac, and ECPR) to differentiate costs per indication.

\section{Methods}

This study was performed according to the Preferred Reporting Items for Systematic Reviews and Meta-Analysis (PRISMA) guidelines [15], and is listed in the PROSPERO register (registration number CRD42020167456.

\subsection{Study Eligibility Criteria}

To qualify for inclusion, studies had to report on hospital costs of ECMO in adults (age $\geq 18$ years). We included any type of study (e.g. randomized trial or observational cohort). Exclusion criteria for this review were studies that involved animals, and studies on neonates, children and adolescents. Studies with a model-based cost analysis were also excluded, as were correspondence/commentaries, reviews, and studies in which full text was not available, as well as studies written in languages other than English or Dutch.

\subsection{Search Criteria}

A medical information specialist conducted a systematic search of the PubMed/MEDLINE (OVID), EMBASE (OVID), and Web of Science databases from inception to 4 March 2020. The full search criteria are available in Supplementary Appendix 1. In summary, we integrated various search terms containing 'extracorporeal membrane oxygenation' combined with 'costs'. Similar terms or phrases were added to the search terms, i.e. 'extracorporeal life support' or 'ECMO' or 'ECLS' combined with 'costs'. Search results from each database were compiled using Endnote 9.2 software and all duplicates were removed.

\subsection{Study Selection}

Two reviewers (AOL-H and OvM) independently screened all titles and abstracts. After selecting articles for full-text screening, any disagreements regarding inclusion or exclusion were discussed. The selected papers were then independently screened (by AOL-H and OvM) in full text and were included for data extraction if they met the selection criteria. Disagreements regarding eligibility were discussed and any discrepancies were resolved by a third reviewer (WMvdB).

\subsection{Data Extraction}

All data extraction was completed by one author (AOL-H) using a predefined standardized data extraction form. Data extraction included study characteristics, patient population, ECMO type and duration, and study design, data collection 
timeframe, costing perspective, information on costs, prospective or retrospective collection, main cost inclusions, main cost exclusions, and currency. In cases where data were missing, we attempted to obtain this information by contacting the first author. The primary goal was to determine the total costs of treatment during the hospital stay for each diagnosis category where ECMO was used. If information was available on the total costs for ECMO patients and a control group, we calculated the incremental costs of ECMO. All costs are reported in 2019 US $\$$ values, unless otherwise specified. In most studies, the currency year was mentioned; however, in cases where this information was missing, the authors of the study were contacted to determine the year. In the event of no response, the currency year was assumed to be the last year in which data were collected. For converting the different currencies to 2019 US\$, we used the method of first inflating costs to 2019 in the original currency, then converting values to 2019 US\$ values, using the gross domestic product (GDP) purchasing power parities (PPP) index. General consumer price indices for each country were used to inflate each presented value to the 2019 value of the given currency. All PPPs and inflation data were taken from the Organization for Economic Co-operation and Development [16]. If studies presented costs in US\$ values rather than in the currency of the country in which the study took place, costs were first converted back to the currency of the original country (using the PPP for the corresponding year), inflated, and then converted back to US\$ values. If charges were reported, these were also inflated to 2019 US\$ values, using the same consumer price indices.

To compare studies reporting charges with studies reporting costs, charges were converted to costs using a 10-year average (2004-2014) of the urban Medicare cost-to-charge ratios (CCRs). Urban CCRs were selected, as ECMO is a highly regionalized therapy that is typically concentrated in large academic centers [3].

\section{Results}

\subsection{Study Selection}

A total of 1768 unique articles were retrieved in our search. We assessed 74 full-text articles for eligibility, resulting in 14 articles being included in this review. The reasons for exclusion are explained in Fig. 1. One study was a prospective randomized controlled trial, while all other studies had an observational design (Table 1). Publication year ranged from 2009 to 2019 (six papers). The collection time period, design, age, number of patients, and diagnosis categories are reported in Table 1.

\subsection{Study Characteristics}

Six of the included studies were from the US, of which five studies used the National Inpatient Sample (NIS). The NIS is the largest collection of all-payer hospital discharges in the US and has been validated extensively in the medical literature [17]. Five papers were from Europe and one each from Japan, Australia, and Taiwan. Sample size ranged from 16 to $18,684[12,18]$. Four studies focused exclusively on ECPR.

\subsection{Perspective and Timing of Cost Collection}

One paper exclusively used prospective cost data collection (i.e. costs were collected while the patient was in the hospital receiving treatment) [4], while all other papers used retrospective data collection. Five US papers reported charges rather than costs of all used data from a national database [18-21, 25], and one US paper provided both charges and costs; we used the latter in this review [9]. Five papers specifically stated a perspective for the cost analysis. The hospital perspective was stated in two papers, followed by the health service perspective $(n=3)$. Of those papers that used the health care service perspective, one was from the UK, one was from the Czech Republic, and one was from Australia. The remaining papers included only costs or charges for in-hospital treatment with ECMO, and were thus interpreted as using the hospital perspective for cost collection.

\subsection{Duration of Extracorporeal Membrane Oxygenation (ECMO)}

Seven studies provided information on the duration of ECMO (Table 2). Five studies provided mean values, one study provided a median value, and one study provided both. The duration of ECMO is not available in the NIS database. Table 2 also reports on length of stay and mortality.

\subsection{Costs and Charges}

Table 3 presents the total costs and charges for an entire hospitalization when ECMO was used, while Fig. 2 presents a summary of costs.

\subsubsection{US Studies}

The reported costs in the US study were US $\$ 318,187$ [9]. The mean charges ranged from US $\$ 154,215$ to US $\$ 868,979$, and the calculated costs ranged from US $\$ 59,381$ to US $\$ 334,608$. Bailey et al. studied outcome and cost by institutional volume [18]. The mean costs were higher in high-volume hospitals than in medium- and low-volume hospitals, and length of stay was also longer in high-volume hospitals than in medium- and low-volume hospitals. The 
Fig. 1 Study selection

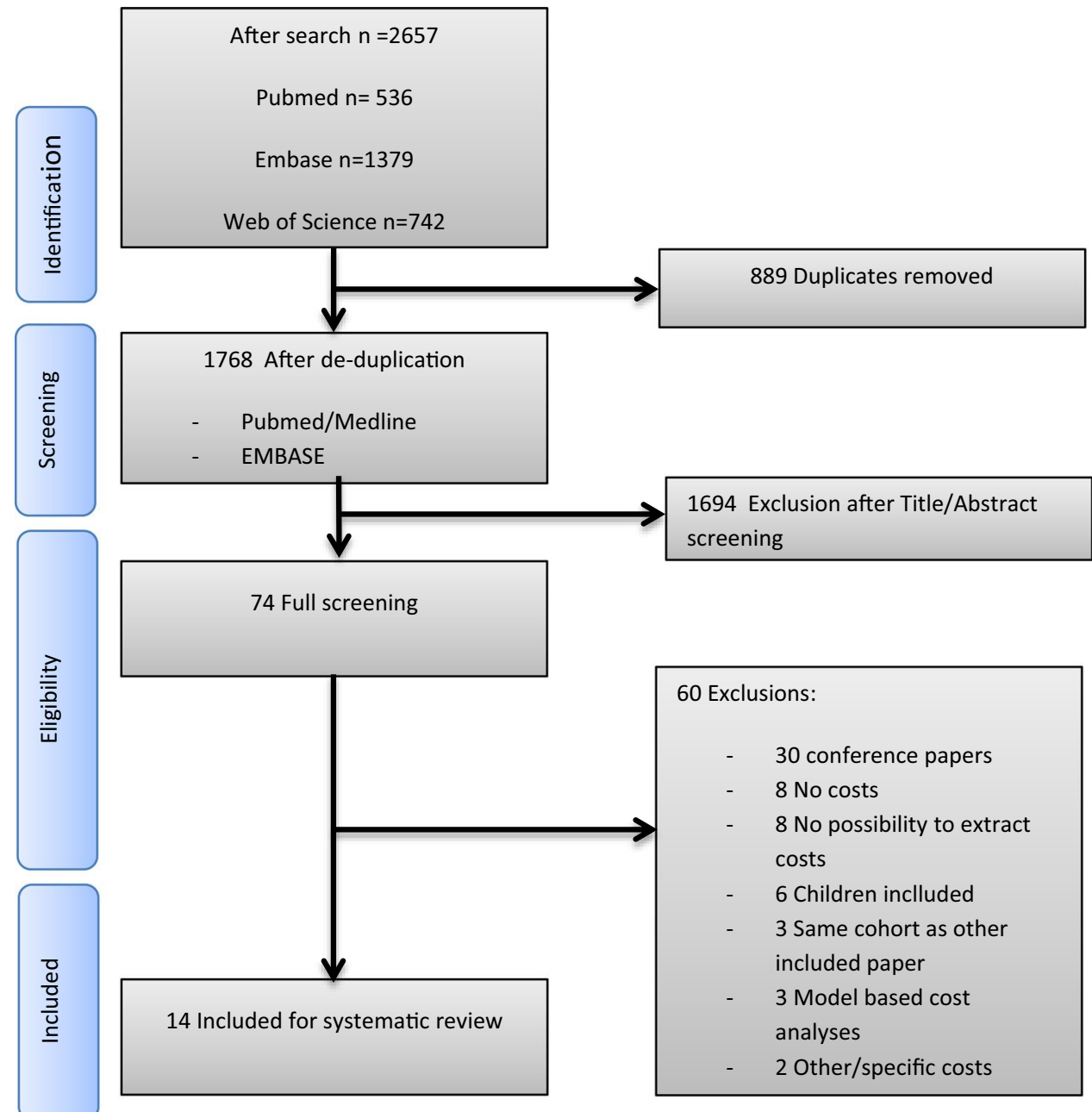

in-hospital mortality increased from low- to medium- to high-volume. A US study reporting on five age groups of patients with cardiogenic shock found that the youngest age cohort had the highest costs. This is most likely explained by the longest length of stay in hospital, with the lowest mortality in this age cohort [20]. To attempt correction of the large variation in cost for the length of stay in hospital, the total costs were divided by days in hospital (Table 3). For the US studies, the costs per day in hospital ranged between a mean of US\$4584-US\$11,524 and a median of US\$3942-US\$13,384.

\subsubsection{Non-US Studies}

The mean total costs of treatment ranged from US\$22,305 to US\$161,532. The study by Kawashima et al. reported on costs according to first documented rhythm in ECPR patients [11], with median costs of US\$22,305 in asystole/ pulseless electrical activity (PEA) patients and US\$30,553 in patients presenting with ventricle tachycardia/ventricle fibrillation (VT/VF). The study by Jäämaa-Holmberg et al. provided a median cost of US\$187,282 [13], and for the non-US studies, the costs ranged between a mean of US $\$ 851$ and US\$4615. Jäämaa-Holmberg provided a median cost of US\$5852 per day in hospital [13].

\subsection{Distribution of Costs}

Five studies provided information on the distribution of the total costs of treatment when ECMO was used. Braune et al. studied extracorporeal carbon dioxide removal $\left(\mathrm{ECCO}_{2} \mathrm{R}\right)$ in hypercapnic patients not responding to noninvasive ventilation [21]. The average cost of the $\mathrm{ECCO}_{2} \mathrm{R}$ treatment included in the intensive care unit (ICU) cost was $18 \%$ of the total hospital cost. In the ECPR study by Buriskova et al., materials and pharmaceuticals were the largest cost items (51\%) [12]; the cost of the ECMO system (consumables and maintenance) was $19.5 \%$ and personnel costs were $11 \%$. In the ECPR study by Dennis et al., ECMO-related costs for survivors were $18 \%$, and $48 \%$ for non-survivors [10]. For survivors, costs relating to days in the ICU and in hospital were responsible 
Table 1 Study characteristics

\begin{tabular}{|c|c|c|c|c|c|c|c|c|c|}
\hline First author & $\begin{array}{l}\text { Year of } \\
\text { publica- } \\
\text { tion }\end{array}$ & Country & $\begin{array}{l}\text { Costing per- } \\
\text { spective }\end{array}$ & Design & $\begin{array}{l}\text { Single } \\
\text { center/multi- } \\
\text { center }\end{array}$ & Time period & Age & $\begin{array}{l}\text { No. of } \\
\text { patients }\end{array}$ & Diagnosis \\
\hline Aiello [19] & 2017 & US & Hospital & NIS & Multi & 2005-2012 & $56.1 \pm 15.8$ & 446 & $\begin{array}{l}\text { Congenital } \\
\text { heart sur- } \\
\text { gery }\end{array}$ \\
\hline Bailey [18] & 2018 & US & Hospital & NIS & Multi & 2008-2014 & $\begin{array}{l}55.3 \pm 17.6 \\
\quad \text { (low- } \\
\text { volume } \\
\text { hospital) } \\
53.1 \pm 16.5 \\
\text { (medium- } \\
\text { volume } \\
\text { hospital) } \\
52.1 \pm 16.8 \\
\text { (high- } \\
\text { volume } \\
\text { hospital) }\end{array}$ & 18,684 & $\begin{array}{l}\text { Post-cardiot- } \\
\text { omy, heart } \\
\text { transplant, } \\
\text { lung trans- } \\
\text { plant, CS, } \\
\text { respiratory } \\
\text { failure }\end{array}$ \\
\hline Bharmal [9] & 2019 & US & Hospital & & Single & 2012-2018 & $\begin{array}{l}52.5 \pm 16.3 \\
55.0(46.3- \\
63.3)\end{array}$ & 32 & ECPR \\
\hline Braune [22] & 2015 & Germany & Hospital & & Multi & 2007-2010 & $58(27-80)$ & 21 & $\begin{array}{l}\text { Chronic } \\
\text { respiratory } \\
\text { disease }\end{array}$ \\
\hline $\begin{array}{l}\text { Buriskova } \\
\text { [12] }\end{array}$ & 2019 & $\begin{array}{l}\text { Czech Repub- } \\
\text { lic }\end{array}$ & Healthcare & & Single & 2009-2014 & & 16 & ECPR \\
\hline Chung [20] & 2019 & US & Hospital & NIS & Multi & 2004-2016 & $54.8 \pm 15.4$ & 3094 & $\mathrm{CS}$ \\
\hline Dennis [10] & 2019 & Australia & Healthcare & & Single & 2009-2018 & $51.9 \pm 13.6$ & 62 & ECPR \\
\hline Hayanga [21] & 2017 & US & Hospital & NIS & Multi & 2000-2011 & $51.4 \pm 1.0$ & 658 & $\begin{array}{l}\text { Lung trans- } \\
\text { plantation }\end{array}$ \\
\hline $\begin{array}{l}\text { Jäämaa- } \\
\text { Holmberg } \\
\text { [13] }\end{array}$ & 2019 & Finland & Hospital & & Single & 2013-2017 & $52.1 \pm 11.7$ & 102 & CS or CA \\
\hline $\begin{array}{l}\text { Kawashima } \\
\text { [11] }\end{array}$ & 2019 & Japan & Hospital & & Single & 2008-2016 & $\begin{array}{l}66(52-74) \\
\text { VF/VT } \\
64(53.5- \\
73.5) \text { Asy/ } \\
\text { PEA }\end{array}$ & 120 & ECPR \\
\hline Maxwell [25] & 2014 & US & Hospital & NIS & Multi & 1998-2009 & $53.9 \pm 0.4$ & 8752 & $\begin{array}{l}\text { Post-cardiot- } \\
\text { omy, heart } \\
\text { transplant, } \\
\text { lung trans- } \\
\text { plant, CS, } \\
\text { respiratory } \\
\text { failure }\end{array}$ \\
\hline $\begin{array}{l}\text { Oude } \\
\text { Lansink- } \\
\text { Hartgring } \\
{[23]}\end{array}$ & 2016 & Netherlands & Hospital & & Single & 2010-2013 & $46 \pm 15$ & 67 & $\begin{array}{l}\text { Respiratory } \\
\text { bridge to } \\
\text { recovery, } \\
\text { respiratory } \\
\text { bridge to } \\
\text { transplant, } \\
\text { cardiac } \\
\text { bridge to } \\
\text { recovery, } \\
\text { cardiac } \\
\text { bridge to } \\
\text { transplant, } \\
\text { post- } \\
\text { cardiotomy, } \\
\text { ECPR }\end{array}$ \\
\hline
\end{tabular}


Table 1 (continued)

\begin{tabular}{|c|c|c|c|c|c|c|c|c|c|}
\hline First author & $\begin{array}{l}\text { Year of } \\
\text { publica- } \\
\text { tion }\end{array}$ & Country & $\begin{array}{l}\text { Costing per- } \\
\text { spective }\end{array}$ & Design & $\begin{array}{l}\text { Single } \\
\text { center/multi- } \\
\text { center }\end{array}$ & Time period & Age & $\begin{array}{l}\text { No. of } \\
\text { patients }\end{array}$ & Diagnosis \\
\hline Peek [4] & 2009 & UK & Healthcare & RCT & Multi & 2001-2006 & $39.9 \pm 13.4$ & 90 & ARDS \\
\hline Tseng [24] & 2011 & Taiwan & Hospital & & Single & 2008-2009 & $56 \pm 18$ & 72 & $\begin{array}{l}\text { Post-cardi- } \\
\text { otomy CS, } \\
\text { non-post- } \\
\text { cardiotomy } \\
\text { CS or CA, } \\
\text { ARDS }\end{array}$ \\
\hline
\end{tabular}

US United States, NIS national inpatient sample, $R C T$ randomized controlled trial, ECPR extracorporeal cardiopulmonary resuscitation, $C S$ cardiogenic shock, $C A$ cardiac arrest, $V T$ ventricle tachycardia, $V F$ ventricle fibrillation, Asy asystole, $P E A$ pulseless electrical activity, $A R D S$ adult respiratory distress syndrome

Table 2 Outcome parameters

\begin{tabular}{|c|c|c|c|c|}
\hline First author & Duration of ECMO (days) & $\begin{array}{l}\text { Length of stay } \\
\text { in the ICU } \\
\text { (days) }\end{array}$ & Length of stay in hospital (days) & In-hospital mortality (\%) \\
\hline \multicolumn{5}{|l|}{ Mean } \\
\hline Aiello [19] & & & $23.9 \pm 11.9$ & 62.6 \\
\hline Bailey [18] & & & $\begin{array}{l}\text { Low-volume hospital, } 7 \text { (3-17) } \\
\text { Medium-volume hospital, } 13 \\
\quad(5-28) \\
\text { High-volume hospital, } 16 \\
\quad(6-33)\end{array}$ & $\begin{array}{l}\text { Low-volume hospital, } 43.7 \\
\text { Medium-volume hospital, } 50.3 \\
\text { High-volume hospital, 55.6 }\end{array}$ \\
\hline Bharmal [9] & $2.8 \pm 2.4$ & $11.5 \pm 13.9$ & & 84 \\
\hline Dennis [10] & $3.8 \pm 4.0$ & $5.8 \pm 9.6$ & $12.0 \pm 21.8$ & 60 \\
\hline Jäämaa-Holmberg [13] & $6 \pm 6$ & & $32 \pm 38$ & 34,3 \\
\hline Maxwell [25] & & & $18.3 \pm 1.3$ & $33.1-52.9$ \\
\hline Oude Lansink-Hartgring [23] & $5.5 \pm 6.8$ & $18 \pm 22$ & $38 \pm 45$ & 68 \\
\hline Tseng [24] & $7.2(0.2-24)$ & & $50(1-201)$ & 57 \\
\hline \multicolumn{5}{|l|}{ Median } \\
\hline Bharmal [9] & $2.1(0.9-3.8)$ & $4.3(2.1-19.3)$ & & 84 \\
\hline Braune [22] & $9(1-116)$ & $15(4-137)$ & $23(4-137)$ & - \\
\hline Chung [20] & & & $14(5-29)$ & 57.7 \\
\hline Hayanga [21] & & & $25(11-46)$ & - \\
\hline Kawashima [11] & & & & $\begin{array}{l}\text { VT/VF: } 61 \\
\text { Asy/PEA: } 83.6\end{array}$ \\
\hline Peek [4] & $9.0(6.0-16.0)$ & & $35.0(15.6-74.0)$ & 63 \\
\hline
\end{tabular}

$E C M O$ extracorporeal membrane oxygenation, $I C U$ intensive care unit, $V T$ ventricle tachycardia, $V F$ ventricle fibrillation, $A s y$ asystole, $P E A$ pulseless electrical activity

for $68 \%$ of the total cost. In the study by Oude LansinkHartgring et al., nursing days constituted $52 \%$ of the total costs [23]. The cost of ECLS therapy (procedures and costs of daily surcharge) was $11 \%$ of the total costs, and the costs for surgeries, blood products, and renal replacement therapy were $12 \%, 7 \%$, and $4 \%$, respectively. In the study by Tseng et al., a breakdown of the total hospital costs showed that the costs spent on personnel constituted $41 \%$ of the total costs, and the costs spent on disposable items, medications, laboratory and radiology tests, blood products, and renal replacement therapy constituted $26 \%$, $13 \%, 10 \%, 8 \%$, and $2 \%$ of the total costs, respectively [24].

\subsection{Additional Costs of ECMO}

In four studies, the incremental difference in total costs associated with ECMO were reported-two US studies and two studies from Europe. In three studies, the additional costs were higher than the total costs of the non-ECMO group [4, 
Table 3 Total hospital costs

\begin{tabular}{|c|c|c|c|c|c|c|c|c|c|}
\hline First author & Country & Diagnosis & Currency & Year & $\begin{array}{l}\text { Total costs (given } \\
\text { currency) }\end{array}$ & $\begin{array}{l}\text { Total charges } \\
\text { (given cur- } \\
\text { rency) }\end{array}$ & $\begin{array}{l}\text { Costs in } 2019 \\
\text { US\$ }\end{array}$ & $\begin{array}{l}\text { Charges to costs } \\
\text { in } 2019 \text { US\$ }\end{array}$ & $\begin{array}{l}\text { Cost } \\
\text { per day } \\
\text { in hos- } \\
\text { pital }\end{array}$ \\
\hline \multicolumn{10}{|l|}{ Mean } \\
\hline Aiello [19] & US & $\begin{array}{l}\text { Congenital heart } \\
\text { surgery }\end{array}$ & US\$ & 2012 & & 642,410 & & 275,446 & 11,524 \\
\hline Bailey [18] & US & $\begin{array}{l}\text { Post-cardiotomy, } \\
\text { heart trans- } \\
\text { plant, lung } \\
\text { transplant, CS, } \\
\text { respiratory } \\
\text { failure }\end{array}$ & US\$ & 2014 & & $\begin{array}{c}\text { Low-volume } \\
\text { hospital, } \\
142,802 \\
\text { Medium- } \\
\text { volume } \\
\text { hospital, } \\
\text { 166,457 } \\
\text { High-volume } \\
\text { hospital, } \\
176,397\end{array}$ & & $\begin{array}{l}59,381 \\
69,218 \\
73,351\end{array}$ & $\begin{array}{l}8483 \\
5324 \\
4584\end{array}$ \\
\hline Maxwell [25] & US & $\begin{array}{l}\text { Post-cardiotomy, } \\
\text { heart trans- } \\
\text { plant, lung } \\
\text { transplant, CS, } \\
\text { respiratory } \\
\text { failure }\end{array}$ & US\$ & 2009 & & 344,009 & & 157,852 & 8625 \\
\hline Bharmal [9] & US & ECPR & US\$ & 2018 & 312,525 & & 318,187 & & NA \\
\hline Braune [22] & Germany & $\begin{array}{l}\text { Chronic respira- } \\
\text { tory disease }\end{array}$ & Euro & 2013 & 41,134 & & 60,482 & & 2629 \\
\hline Buriskova [12] & Czech Republic & ECPR & CZK & 2013 & 788,432 & & 67,682 & & NA \\
\hline Dennis [10] & Australia & ECPR & AU\$ & 2016 & 75,165 & & 53,821 & & 4484 \\
\hline $\begin{array}{l}\text { Kawashima } \\
\text { [11] }\end{array}$ & Japan & ECPR & US\$ & 2016 & $\begin{array}{l}31,736 \text { VT/VF } \\
23,564 \text { Asy/PEA }\end{array}$ & & $\begin{array}{l}\text { 30,553 VT/VF } \\
22,305 \text { Asy/PEA }\end{array}$ & & NA \\
\hline $\begin{array}{l}\text { Oude Lansink- } \\
\text { Hartgring } \\
\text { [23] }\end{array}$ & Netherlands & $\begin{array}{l}\text { Respiratory } \\
\text { bridge to } \\
\text { recovery, res- } \\
\text { piratory bridge } \\
\text { to transplant, } \\
\text { cardiac bridge } \\
\text { to recovery, } \\
\text { cardiac bridge } \\
\text { to transplant, } \\
\text { post-cardiot- } \\
\text { omy, ECPR }\end{array}$ & Euro & 2013 & 106,263 & & 156,245 & & 4111 \\
\hline Peek [4] & UK & ARDS & GBP & 2005 & 73,979 & & 161,532 & & 4615 \\
\hline Tseng [24] & Taiwan & $\begin{array}{l}\text { Post-cardiotomy } \\
\text { CS, non-post- } \\
\text { cardiotomy CS } \\
\text { or CA, ARDS }\end{array}$ & US\$ & 2010 & 39,845 & & 42,567 & & 851 \\
\hline \multicolumn{10}{|l|}{ Median } \\
\hline Chung [20] & US & $\begin{array}{l}\text { Cardiogenic } \\
\text { shock }\end{array}$ & US\$ & 2016 & & 134,573 & & 55,197 & 3942 \\
\hline Hayanga [21] & US & $\begin{array}{l}\text { Lung transplan- } \\
\text { tation }\end{array}$ & US\$ & 2012 & & 780,391 & & 334,608 & 13,384 \\
\hline $\begin{array}{l}\text { Jäämaa-Holm- } \\
\text { berg [13] }\end{array}$ & Finland & $\mathrm{CS}$ or $\mathrm{CA}$ & Euro & 2017 & 129,967 & & 187,282 & & 5852 \\
\hline
\end{tabular}

US United States, US\$ United States dollar, CZK Czech koruna, AU\$ Australian dollar, GBP Pound Sterling, ECPR extracorporeal cardiopulmonary resuscitation, $C S$ cardiogenic shock, $C A$ cardiac arrest, $V T$ ventricle tachycardia, $V F$ ventricle fibrillation, $A s y$ asystole, $P E A$ pulseless electrical activity, $A R D S$ adult respiratory distress syndrome, $N A$ length of hospital stay was not available

19]. In a study in adults undergoing congenital heart surgery, the median additional cost of ECMO was US\$200,658. In that study, the length of stay in hospital was significantly longer in the ECMO group (11.5 vs. 23.9 days; $p<0.001)$ and mortality in the ECMO group was also significantly higher (4.5 vs. $62.6 \% ; p<0.001)$ [19]. In lung transplant recipients, the median additional cost of the ECMO group was US\$195,566. For patients with ECMO support in lung 
Fig. 2 Costs are represented as mean costs. * indicates median costs, \# indicates costs for high volume hospital, and $\sim$ indicates costs for patients with ventricle tachycardia or ventricle fibrillation

\section{Costs in USD 2019}

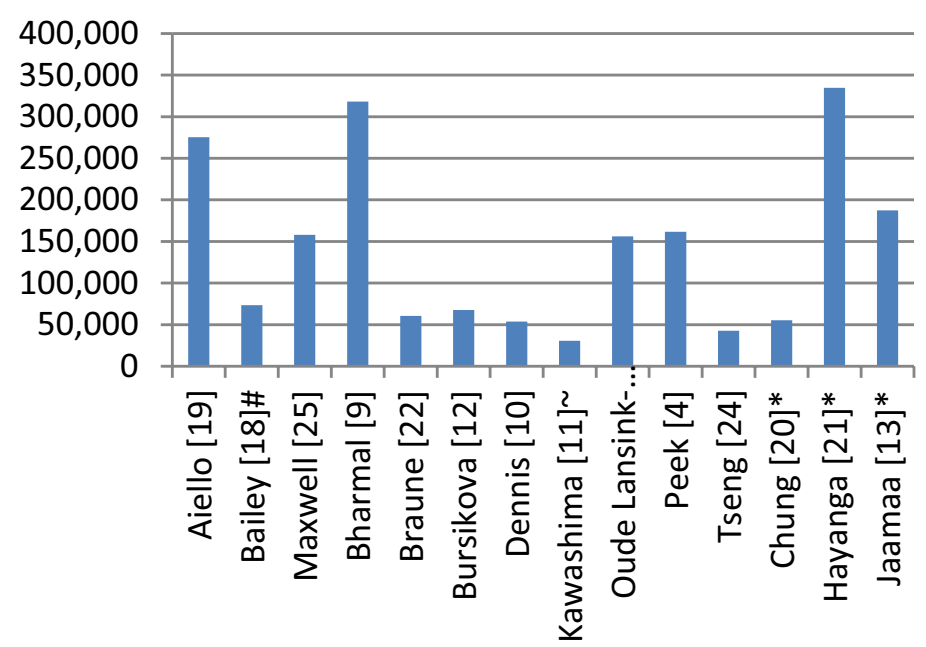

transplant recipients, the underlying diagnosis was more often idiopathic pulmonary fibrosis or pulmonary hypertension [21]. The ECMO group had a longer median length of stay ( 25 vs. 15 days; $p<0.001$ ); however, lung allocation scores as a marker of severity pretransplant and in-hospital mortality were not reported in that study. In the prospective study on severe respiratory failure in the UK, the incremental costs were US\$89,698, also higher than the control group [4]. In the $\mathrm{ECCO}_{2} \mathrm{R}$ study only, the incremental costs were US $\$ 2518$ lower, possibly due to the shorter length of stay in the ICU and in hospital [22].

\subsection{Hospital Costs Per Diagnosis}

In a study on ECPR patients, the median operating costs were US\$70,994 for out-of-hospital cardiac arrest (OHCA) and US\$179,904 for in-hospital cardiac arrest (IHCA) [9], while in an Australian ECPR study, the mean hospital costs were US $\$ 42,658$ for OHCA and US $\$ 62,700$ for IHCA [10]. In another ECPR study, the median total hospital costs were reported according to first documented rhythm [11]. The cost for patients presenting with VT/VF was US\$30,553, and US\$22,305 for patients presenting with asystole/PEA. Costs for other studies are reported in Table 4. The mean cost for ECPR was US\$81,715. Four studies reported on patients receiving ECMO post-cardiotomy [13, 23-25], with a mean cost of US $\$ 101,043$, and four studies reported on patients receiving respiratory ECMO (no $\mathrm{ECCO}_{2} \mathrm{R}$ ) [4, 23-25], with a mean cost of US\$132,496. Two studies reported on patients receiving ECMO after lung transplant $[21,25]$, with a mean cost of US $\$ 328,588$. In a study of patients in cardiogenic shock or cardiac arrest, the costs were reported according to the etiology [13]. The median hospital costs were US $\$ 292,100$ for post heart transplant, US\$187,357 for cardiomyopathy, US\$184,376
Table 4 Hospital costs according to diagnosis

\begin{tabular}{lll}
\hline First author & Diagnosis & Costs in 2019 US\$ \\
\hline Kawashima [11] & ECPR & $22,305-30,553$ \\
Tseng [24] & ECPR & 33,140 \\
Dennis [10] & ECPR & 53,821 \\
Buriskova [12] & ECPR & 67,682 \\
Oude Lansink-Hartgring & ECPR & 69,538 \\
$\quad$ [23] & & \\
Bharmal [9] & ECPR & 318,187 \\
Tseng [24] & Post-cardiotomy & 43,245 \\
Oude Lansink-Hartgring & Post-cardiotomy & 91,732 \\
[23] & & \\
Maxwell [25] & Post-cardiotomy & 125,466 \\
Jäämaa-Holmberg [13] & Post-cardiotomy & 143,729 \\
Chung [20] & Cardiogenic shock & 55,197 \\
Maxwell [25] & Cardiogenic shock & 161,776 \\
Jäämaa-Holmberg [13] & Cardiogenic shock & 187,282 \\
& and cardiac & \\
Maxwell [25] & arrest & 322,568 \\
Hayanga [21] & Lung transplant & 334,608 \\
Tseng [24] & Lung transplant & 54,336 \\
Oude Lansink-Hartgring & Respiratory & 120,920 \\
[23] & Respiratory & 161,532 \\
Peek [4] & Respiratory & 193,198 \\
Maxwell [25] & Respiratory & \\
\hline
\end{tabular}

Costs are expressed as means, except Jäämaa-Holmberg [13], Chung [20] and Hayanga [21], which are expressed as median costs

$E C P R$ extracorporeal cardiopulmonary resuscitation, US\$ United States dollar 
for myocarditis, US $\$ 143,729$ post-cardiotomy, and US $\$ 63,451$ for acute coronary syndrome. Costs for other studies reporting on cardiogenic shock are reported in Table 4. The mean cost for ECMO in cardiogenic shock was US\$134,751. In a study where the ECMO indication was formulated as intent of bridging, the mean total cost for respiratory bridge to recovery was US\$147,850, and the mean costs for respiratory bridge to transplant, cardiac bridge to recovery, cardiac post-cardiotomy, and ECPR were US\$205,080, US\$93,352, US\$91,732, and US $\$ 69,538$, respectively [23]. In patients with hypercapnic ventilatory insufficiency, the mean total cost was US $\$ 27,933$ for patients with chronic obstructive pulmonary disease [22].

\section{Discussion}

ECMO therapy is an advanced and expensive technology, although reported costs differ considerably depending on ECMO indication and whether charges or costs are measured. ECMO is a therapy that has been used increasingly in the last two decades, although there are no randomized controlled trials proving efficacy of ECMO therapy other than the Cesar trial, which shows patient benefit from referral to an ECMO center, not ECMO therapy per se [4]. This increased use without solid scientific support makes the costs an important topic in the discussion of this subject. The majority of the data collection for the studies in this review was undertaken in the last decade, reflecting the increased use of ECMO.

\subsection{Costs and Charges}

The US health care costs, both as a proportion of the GDP $(16.9 \%)$ and per person (US\$10,586), are among the highest in the world and are still rising. Administrative costs and prices of labor (including physicians and hospital services) and goods (including pharmaceuticals and devices) appeared to be the main drivers of the differences in spending [26]. Five studies in this review originated from the US, with data from the NIS database, which provides charges. A review on costing methodologies in critical care showed that almost $40 \%$ of the included studies used hospital charges as a surrogate for actual costs [27]. The relation between provided charges and costs is complicated. For the purpose of this review, the charges were converted to costs using the CCR, a value that varies per procedure and per region. ECMO is a treatment not offered in all centers, which could lead to higher charges. Currently, this method is the best option but it has its limitations. In the single US study $(n=320)$ providing both charges and costs, the difference between comparing the CCR and costs amounted to 5\% [9]. For the US studies, the costs for ECMO seem higher than in the non-US studies. In particular, the smaller studies reporting on specific patient groups (congenital heart surgery, ECPR, and lung transplantation) instead of more mixed cohorts, report higher costs $[9,19,21]$. Results for the costs in US hospitals should therefore be interpreted with caution and costs cannot simply be translated to non-US countries.

\subsection{Distribution of Costs}

In five non-US studies, the reported costs are given with a breakdown in categories; however, unfortunately, the labeling of the categories is not standardized. The costs of ECMO equipment varied between 11 and 20\% [10, $12,22]$. In two studies, personnel costs were reported as the major cost factor [23, 24]. The comparison of studies that reported on the distribution of costs is hampered by the differences in definition and reporting. There is even a difference in reporting personnel costs; in the US, the personnel attending the ECMO is costed to the overall hospital cost.

In general, ICU length of stay is the most important factor in total costs within the ICU, followed by the use of mechanical ventilation. Higher ICU mortality is also associated with significant higher costs, which might be explained by the considerable number of resources used at the end of life [28]. Another option is that higher costs are explained by a tendency to continue treatment based on the time and effort invested (sunk cost effect) [29].

\subsection{Additional Costs of ECMO}

In two US studies, the additional costs of the ECMO group compared with the non-ECMO group is higher than the total costs of the non-ECMO group. In the study on adults undergoing congenital heart surgery, the length of stay in hospital is significantly longer in the ECMO group [19], which illustrates the fact that in this patient category, the need for ECMO is related to the severity of the underlying cardiac diagnosis. The higher mean additional costs for patients allocated to consideration for ECMO treatment in severe adult respiratory failure in the only randomized trial in this review might also be due to longer stay in hospital [4]. The additional costs of ECMO in the study on ECMO to avoid intubation are low and are probably related to the shorter length of stay in these patients [22].

\subsection{Costs Per Diagnosis}

The enormous variation in ECMO-associated costs is hardly surprising considering the many underlying illnesses leading to cardiorespiratory failure for which ECMO 
can be employed. ECPR is a standardized patient population with few variables (presenting rhythm, location of arrest), with the highest mortality rate with short duration of ECMO needing few costly additional treatments other than percutaneous myocardial revascularization (costs: US\$22,305-US\$302,493) and yet the variation in costs is great $[9-12,23,24]$. In the study with the highest reported costs (the only US study), significant variation was also seen among survivors, with higher costs for use of the Centrimag pump and for IHCA [9]. For ECPR patients presenting with asystole, the prognosis is often dictated by the extend of neurological damage, leading to the early withdrawal of treatment. At the other end of the spectrum, one finds patients undergoing heart or lung transplantation with ECMO support, with costs varying between US $\$ 205,080$ and US $\$ 331,355[13,23,25]$. Another reasonably homogeneous group of patients are patients requiring ECMO postcardiotomy, with costs varying between US $\$ 91,732$ and US\$143,729 [13, 23, 25].

\subsection{Limitations}

This review is limited mostly by the use of charges instead of costs in almost half of the included studies; however, since all but one US study used charges, restricting the analyses to studies reporting costs would only limit the generalizability of this review. We used a standard CCR to convert charges to costs to make a comparison possible, although this should be interpreted with caution. Unfortunately, there is little consistency in the definition of subgroups and breakdown of costs into different categories. This field of research needs additional studies showing mean costs stratified by treatment indication, comorbidities, survivor status, length of stay in the ICU, hospital, on pump, and costs for comparators to make a robust analysis of this therapy.

Hospital costs should also not be interpreted without keeping track of the outcome (mortality). As mentioned previously, cost-effectiveness studies are urgently warranted in the expanding field of ECMO treatment, not only querying whether ECMO works but also by how much does ECMO work, in whom, and at what cost [30]?

\section{Conclusion}

The current literature shows large variation in hospital costs for ECMO support. Although the benefit of ECMO therapy is not beyond any doubt, apart from ECPR there is unlikely to be additional randomized controlled trial evidence, therefore costs and assumed cost effectiveness are important factors in further implementation of ECMO therapy. However, costs vary widely between indications and our results may guide implementation per indication.
Supplementary Information The online version contains supplementary material available at https://doi.org/10.1007/s41669-021-00272-9.

Acknowledgements Members of the Dutch Extracorporeal Life Support Study Group: Annemieke Oude Lansink-Hartgring, Department of Critical Care, University of Groningen, University Medical Center Groningen, Groningen, The Netherlands. Walter M. van den Bergh, Department of Critical Care, University of Groningen, University Medical Center Groningen, Groningen, The Netherlands. Karin M. Vermeulen, Department of Epidemiology, University of Groningen, University Medical Center Groningen, Groningen, The Netherlands. Dinis dos Reis Miranda, Department of Intensive Care, Erasmus Medical Center, Rotterdam, The Netherlands. Thijs S.R. Delnoij, Department of Cardiology, Maastricht University Medical Center, Maastricht, The Netherlands. Carlos V. Elzo Kraemer, Department of Intensive Care Medicine, Leiden University Medical Center, Leiden, The Netherlands. Jacinta J. Maas, Department of Intensive Care Medicine, Leiden University Medical Center, Leiden, The Netherlands. Alexander P.J. Vlaar, Department of Intensive Care, Amsterdam University Medical Centers, location Academic Medical Centers, Amsterdam, The Netherlands. Dirk W. Donker, Intensive Care Center, University Medical Center Utrecht, Utrecht, The Netherlands. Erik Scholten, Department of Intensive Care, St. Antonius Hospital, Nieuwegein, The Netherlands. Anja Balzereit, Department of Intensive Care Medicine, Onze Lieve Vrouwe Gasthuis, Amsterdam, The Netherlands. Judith van den Brule, Department of Intensive Care, Radboud University Nijmegen Medical Centre, Nijmegen, The Netherlands. Marijn Kuijpers, Department of Intensive Care, Isala Klinieken, Zwolle, The Netherlands.

\section{Declarations}

Funding This project was made possible by a research grant from ZonMw, received by WvdB.

Conflict of interest Annemieke Oude Lansink-Hartgring, Olivier van Minnen, Karin M. Vermeulen, and Walter M. van den Bergh have no conflicts of interest to declare.

Ethics approval Not applicable.

Consent to participate Not applicable.

Consent for publication Not applicable.

Availability of data All data generated or analyzed during this study are included in this published article and its supplementary information files.

Code Availability Not applicable.

Author contributions All authors contributed to the writing and revision of this article, and reviewed and approved the manuscript. WMB was the overall guarantor of this systematic review.

Open Access This article is licensed under a Creative Commons Attribution-NonCommercial 4.0 International License, which permits any non-commercial use, sharing, adaptation, distribution and reproduction in any medium or format, as long as you give appropriate credit to the original author(s) and the source, provide a link to the Creative Commons licence, and indicate if changes were made. The images or other third party material in this article are included in the article's Creative Commons licence, unless indicated otherwise in a credit line to the material. If material is not included in the article's Creative Commons licence and your intended use is not permitted by statutory 
regulation or exceeds the permitted use, you will need to obtain permission directly from the copyright holder. To view a copy of this licence, visit http://creativecommons.org/licenses/by-nc/4.0/.

\section{References}

1. Brogan TV, Lequier L, Lorusso R, MacLaren G, Peek G, editors. Extracorporeal life support: the ELSO Red Book. 5th Edition. Ann Arbor: Extracorporeal Life Support Organization; 2017.

2. Extracorporeal Life Support Organization. Extracorporeal Life Support Organization ECLS Registry Report Overall Outcomes. 2019. https://www.elso.org/Registry/Statistics.aspx. Accessed 10 Sept 2020.

3. Harvey MJ, Gaies MG, Prosser LA. U.S. and international inhospital costs of extracorporeal membrane oxygenation: a systematic review. Appl Health Econ Health Policy. 2015;13(4):341-57. https://doi.org/10.1007/s40258-015-0170-9.

4. Peek GJ, Mugford M, Tiruvoipati R, Wilson A, Allen E, Thalanany MM, CESAR trial collaboration, et al. Efficacy and economic assessment of conventional ventilatory support versus extracorporeal membrane oxygenation for severe adult respiratory failure (CESAR): a multicentre randomised controlled trial. Lancet. 2009;374(9698):1351-63. https://doi.org/10.1016/S01406736(09)61069-2.

5. Combes A, Hajage D, Capellier G, Demoule A, Lavoué S, Guervilly C, EOLIA Trial Group, REVA, and ECMONet, et al. Extracorporeal membrane oxygenation for severe acute respiratory distress syndrome. N Engl J Med. 2018;378(21):1965-75. https://doi. org/10.1056/NEJMoa1800385.

6. Combes A, Brodie D, Chen YS, Fan E, Henriques JP, Hodgson $\mathrm{C}$, et al. The ICM research agenda on extracorporeal life support. Intensive Care Med. 2017;43(9):1306-18. https://doi.org/10.1007/ s00134-017-4803-3.

7. Brodie D, Vincent JL, Brochard LJ, Combes A, Ferguson ND, Hodgson CL, International ECMO Network (ECMONet), et al. Research in extracorporeal life support: a call to action. Chest. 2018;153(4):788-91. https://doi.org/10.1016/j.chest.2017.12.024.

8. Barrett KA, Hawkins N, Fan E. Economic evaluation of venovenous extracorporeal membrane oxygenation for severe acute respiratory distress syndrome. Crit Care Med. 2019;47(2):186-93. https://doi.org/10.1097/CCM.0000000000003465.

9. Bharmal MI, Venturini JM, Chua RFM, Sharp WW, Beiser DG, Tabit CE, et al. Cost-utility of extracorporeal cardiopulmonary resuscitation in patients with cardiac arrest. Resuscitation. 2019;136:126-30. https://doi.org/10.1016/j.resuscitation.2019.01. 027.

10. Dennis M, Zmudzki F, Burns B, Scott S, Gattas D, Reynolds C, Sydney ECMO Research Interest Group, et al. Cost effectiveness and quality of life analysis of extracorporeal cardiopulmonary resuscitation (ECPR) for refractory cardiac arrest. Resuscitation. 2019;139:49-56. https://doi.org/10.1016/j.resuscitation.2019.03. 021.

11. Kawashima T, Uehara H, Miyagi N, Shimajiri M, Nakamura K, Chinen $\mathrm{T}$, et al. Impact of first documented rhythm on cost-effectiveness of extracorporeal cardiopulmonary resuscitation. Resuscitation. 2019;140:74-80. https://doi.org/10.1016/j.resuscitation. 2019.05.013.

12. Buriskova K, Rogalewicz V, Ostadal P. Cost-effectiveness of extracorporeal cardiopulmonary resuscitation in patients with refractory cardiac arrest. Value Health. 2014;17(7):A488. https:// doi.org/10.1016/j.jval.2014.08.1435.

13. Jäämaa-Holmberg $S$, Salmela $B$, Suojaranta R, Lemstrom KB, Lommi J. Cost-utility of venoarterial extracorporeal membrane oxygenation in cardiogenic shock and cardiac arrest. Eur Heart
J Acute Cardiovasc Care. 2020;9(4):333-41. https://doi.org/10. 1177/2048872619900090.

14. Gravesteijn BY, Schluep M, Voormolen DC, van der Burgh AC, Dos Reis MD, Hoeks SE, et al. Cost-effectiveness of extracorporeal cardiopulmonary resuscitation after in-hospital cardiac arrest: a Markov decision model. Resuscitation. 2019;143:150-7. https:// doi.org/10.1016/j.resuscitation.2019.08.024.

15. Moher D, Liberati A, Tetzlaff J, Altman DG. Preferred reporting items for systematic reviews and meta-analyses: the PRISMA statement. PLoS Med. 2009;6:e1000097.

16. Organization for Economic Co-operation and Development. Purchasing Power Parities for GDP and related indicators. https:// stats.oecd.org. Accessed 29 June 2020.

17. Khera R, Krumholz HM. With great power comes great responsibility: "Big Data" research from the national inpatient sample. Circ Cardiovasc Qual Outcomes. 2017;10(7):e003846. https://doi. org/10.1161/CIRCOUTCOMES.117.003846.

18. Bailey KL, Downey P, Sanaiha Y, Aguayo E, Seo YJ, Shemin RJ, et al. National trends in volume-outcome relationships for extracorporeal membrane oxygenation. J Surg Res. 2018;231:421-7. https://doi.org/10.1016/j.jss.2018.07.012.

19. Aiello S, Loomba RS, Kriz C, Buelow M, Aggarwal S, Arora $\mathrm{RR}$. The need for extracorporeal membrane oxygenation in adults undergoing congenital heart surgery: impact and trends of utilization. Indian J Crit Care Med. 2017;21:547-51.

20. Chung M, Zhao Y, Strom JB, Shen C, Yeh RW. Extracorporeal membrane oxygenation use in cardiogenic shock: impact of age on in-hospital mortality, length of stay, and costs. Crit Care Med. 2019;47(3):e214-21. https://doi.org/10.1097/CCM.0000000000 003631.

21. Hayanga JWA, Shigemura N, Aboagye JK, Ensor C, Dew MA, Hayanga HK, et al. ECMO support in lung transplantation: a contemporary analysis of hospital charges in the United States. Ann Thorac Surg. 2017;104(3):1033-9. https://doi.org/10.1016/j.athor acsur.2017.04.003.

22. Braune S, Burchardi H, Engel M, Nierhaus A, Ebelt H, Metschke $\mathrm{M}$, et al. The use of extracorporeal carbon dioxide removal to avoid intubation in patients failing non-invasive ventilation-a cost analysis. BMC Anesthesiol. 2015;15:160. https://doi.org/10.1186/ s12871-015-0139-0.

23. Oude Lansink-Hartgring A, van den Hengel B, van der Bij W, Erasmus ME, Mariani MA, Rienstra M, Dutch Extracorporeal Life Support Study Group, et al. Hospital costs of extracorporeal life support therapy. Crit Care Med. 2016;44(4):717-23. https:// doi.org/10.1097/CCM.0000000000001477.

24. Tseng YH, Wu MY, Tsai FC, Chen HJ, Lin PJ. Costs associated with extracorporeal life support used in adults: a single-center study. Acta Cardiol Sin. 2011;27(4):221-8.

25. Maxwell BG, Powers AJ, Sheikh AY, Lee PH, Lobato RL, Wong JK. Resource use trends in extracorporeal membrane oxygenation in adults: an analysis of the Nationwide Inpatient Sample 1998-2009. J Thorac Cardiovasc Surg. 2014;148(2):416-21.

26. Papanicolas I, Woskie LR, Jha AK. Health Care spending in the United States and other high-income countries. JAMA. 2018;319(10):1024-39. https://doi.org/10.1001/jama.2018.1150.

27. Pines JM, Fager SS, Milzman DP. A review of costing methodologies in critical care studies. J Crit Care. 2002;17(3):181-7.

28. Kramer AA, Dasta JF, Kane-Gill SL. The impact of mortality on total costs within the ICU. Crit Care Med. 2017;45(9):1457-63.

29. Arkes HR, Blumer C. The psychology of sunk cost. Organ Behav Hum Decis Process. 1985;35(1):124-40.

30. Lewis RJ, Angus DC. Time for clinicians to embrace their inner bayesian? Reanalysis of results of a clinical trial of extracorporeal membrane oxygenation. JAMA. 2018;320(21):2208-10. https:// doi.org/10.1001/jama.2018.16916. 